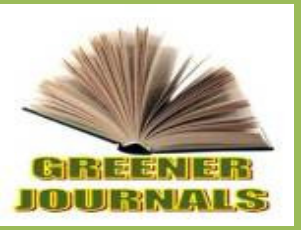

\title{
Physical and Chemical Characterisation of Soils of Anambra State College of Agriculture, Mgbakwu
}

\section{Ejikeme CS $^{1}$ and Nweke IA ${ }^{\star 2}$}

\author{
${ }^{1}$ Anambra State College of Agriculture, Mgbakwu, Nigeria. \\ ${ }^{2}$ Department of Soil Science, Chukwuemeka Odumegwu Ojukwu University, Nigeria.
}

\section{ARTICLE INFO}

Article No.: 102116189

DOI: 10.15580/GJAS.2016.10.102116189

Submitted: 21/10/2016

Accepted: $31 / 10 / 2016$

Published: 30/11/2016

${ }^{*}$ Corresponding Author

Nweke IA

E-mail: nweksoniyke @gmail.com
The physical and chemical characterisation of Anambra State College of Agriculture at Mgbakwu, Awka North Local Government Area was conducted using composite samples from two representative profile pits. Six soil samples were collected from various depths, dried, sieved with $2 \mathrm{~mm}$ sieve and subjected to a routine soil analysis and the characteristics of the soils described. The findings from the study shows that the texture of the soils varied from loamy sand to sand clay loam, with the total sand ranging from $640-840 \mathrm{gkg}^{-1}$, clay from 70 to $290 \mathrm{gkg}^{-1}$ and silt $50-90 \mathrm{gkg}^{-1}$. The soils reaction (pH) is extremely acidic to moderate, ranging from 4.1 to 5.8 . The available phosphorous of the soils is very low, 1.87 to $3.73 \mathrm{mgkg}^{-1}$. The exchangeable bases, organic matter, carbon, cation exchangeable capacity (CEC) and percentage nitrogen of the soils were observed to be low. Generally, the result of the study revealed that the nutrient elements tested were below their critical level and therefore need to be upgraded in soil nutrients through soil amendment to produce maximally.

Keywords:

Agriculture, chemical soil

properties, Mgbakwu, physical soil

properties 


\section{INTRODUCTION}

Land is the surface of the earth including every thing above and beneath it. It is the nature's gift to man. Man's activities on land ranges from agricultural to nonagricultural. Land can be left fallow, put to forest, mined, built or cultivated on to render services to man's needs. Therefore, land use is characterised by the arrangement, activities and input of people occupying a certain land cover type in producing, changing or maintaining it. Akamigbo (2010) postulates that land use involves land management and that management must be planned in order to allocate land to its most suitable use. However, the suitable use of land depends on the inherent characteristics of the land. For instance, agricultural purposes on land depend on soil which serves as a natural medium for crops production. Soil is a natural occurring unconsolidated material on the surface of the earth that has been influenced by parent material, climate, relief and organisms (both micro and macro organisms), all acting over a period of time to produce soil that may differ from the material from which it was derived in physical, chemical, biological and morphological properties. From the definition above, the physical and chemical characterisation of soils of Anambra State College of Agriculture, Mgbakwu, becomes of paramount importance for the necessities of teaching, research and crop production activities.

Anambra State College of Agriculture, Mgbakwu, is located at the heart of Mgbakwu, at the boundary between their thickly populated area and their farm land/undeveloped areas. It has an area of approximately $0.266 \mathrm{~km}^{2}\left(265031 \mathrm{~m}^{2}\right)$. Mgbakwu community is in Awka North Local Government Area of Anambra State. Their area belongs to the south-eastern lowland. The soils of Mgbakwu are derived from coarse parent material of sedimentary rock origin. The town is located on a relatively level land.

The College of Agriculture has been in existence since 1980 s at Igbariam as a Farm Settlement, Anambra East Local Government Area, until the coming of the Anambra State University (Now Chukwuemeka Odumegwu Ojukwu University) into the farm settlement. This led to the relocation of the College of Agriculture in 2004/2005 to Mgbakwu, its permanent base today. Thus, the need for physical and chemical characterisation of soils of the College for effective teaching, research and crop production activities as well as ways to manage and sustain the soils for both present and future uses.

\section{MATERIALS AND METHODS}

\section{Site Location}

Mgbakwu community is located at the approximate coordinates of $06^{\circ} 39^{1} \mathrm{~N}$ and $07^{\circ} 29^{1} \mathrm{E}$ (Duze and Afolabi 1981). It is one of the towns in Awka North Local
Government Area of Anambra State. It is bordered in the east by Ifite Awka, in the north by Ebenebe, in the west by Isu-Aniocha, and in the south by Okpuno.

Mgbakwu has two climate seasons which lasts from April to October, with $2000 \mathrm{~mm}-3000 \mathrm{~mm}$ average rainfall. The dry season in this area lasts from November to March, with an average rainfall amount of $750 \mathrm{~mm}$. There is usually a break in August, the August break.

Generally, the mean annual rainfall of the area is over $2000 \mathrm{~mm}$, the relative humidity of the area in January and July respectively is between $75 \%$ and $95 \%$, while the mean annual temperature fluctuates between $25^{\circ}$ and $27.5^{\circ} \mathrm{C}$. The town falls within the forest zone of the south-eastern Nigeria (Duze and Afolabi 1981). Mgbakwu has an even topography which looks like a level land. As a result, the areas do not have a major erosion problem. The soil parent material is predominantly sedimentary. It belongs to the ferralitic red yellow soils of the humid tropics (Duze and Afolabi 1981).

\section{Field Method}

Flexible grid survey approach was employed to establish two profile pits, which represent the entire area. Three horizons were established on each of the two profile pits up to a depth of $180 \mathrm{~cm}$. Six soil samples were collected from various depths. The profile samples were later subjected to a complete routine analysis, and then used to characterise the Mgbakwu site of the College.

\section{Laboratory procedures}

The whole samples collected were air-dried, sieved with $2 \mathrm{~mm}$ sieve and then used to analyse for the following parameters:

Soil $\mathrm{pH}$ determination was carried out in both distilled water and in potassium chloride $(\mathrm{KCl})$ solution using a soil-liquid ratio of $1: 2.5$. The $\mathrm{pH}$ values were read using a $\mathrm{pH}$ meter. Particle size analysis was conducted using the hydrometer method of Bouyoucous (1934).

Organic carbon and organic matter was determined by Walkley and Black method (1934). The percentage organic matter content was calculated by multiplying the organic carbon value by the conventional "Van Bernmeler" factor of 1.724. Total nitrogen was determined by macro Kjeldahl method of Bremmer and Mulvancy (1982) using $\mathrm{Na}_{2} \mathrm{SO}_{4}$ catalyst mixture.

Exchangeable bases $(\mathrm{Ca}, \mathrm{Mg}, \mathrm{Na}, \mathrm{K})$, the calcium and magnesium were determined by the complex metric titration method (Jackson, 1958), while sodium and potassium were determined in ammonium acetate leachate using the flame photometer. Exchangeable hydrogen and aluminium were determined by titrimetic method using $\mathrm{KCl}$ extract (Mclean, 1982). 
Base saturation was calculated by the dividing the sum of base ( $\mathrm{Ca}, \mathrm{Mg}$ and $\mathrm{K}$ ) by the cation exchange capacity (CEC) and multiplying the quotient by 100 , i.e. TEB $\times 100$

\section{CEC 1}

Available phosphorous was determined by using the Bray 11 method (Bray and Kurtz, 1945). Cation exchange capacity was determined using the ammonium acetate method (Jackson, 1958) while the effective cation exchange capacity was obtained by summing of the exchangeable bases (cations).

\section{RESULTS}

\section{Physical Characterisation}

The ANSCOAM soil falls within the ferralitic red - yellow soil of humid tropical equatorial areas. The geology is of pre - Cambrian basement complex. The soils are generally dark reddish brown to red. There is no cutan, concretion, stone crops, lithic or paralithic layer encountered. The soil texture is generally loamy sand to sandy clay loam soils with clay ranging from 70 -
$290 \mathrm{gkg}^{-1}$ and increased with depth, silt vary irregularly with depth from $50-90$, find sand also vary irregularly from $300-390 \mathrm{gkg}^{-1}$ and coarse sand irregularly with depth from $290-450 \mathrm{gkg}^{-1}$ soil . The total sand $\left(\mathrm{gkg}^{-1}\right)$ generally decreased with depth ranging from $640-$ $840 \mathrm{gkg}^{-1}$. There is completely no gravel or stone outcrop (Table 1).

\section{Chemical characterisation}

The soil pH of Mgbakwu College soil is extremely acidic in $\mathrm{KCl}$ with a range of 4.1 to 4.2 and strongly acidic to moderate in water with a range of 5.5 to 5.8 . The organic matter content of the soil is low, with a value range of 0.06 to $0.77 \%$. The carbon and nitrogen percentage is also low, and varies from 0.04 to $0.45 \%$ and 0.04 to $0.38 \%$ respectively. The exchangeable bases include sodium (Na), potassium (K), calcium $(\mathrm{Ca})$ and magnesium $(\mathrm{Mg})$. The sodium $(\mathrm{Na})$ varies irregularly with depth from 0.11 to $0.51 \mathrm{cmolkg}^{-1}$ soils. The potassium also varies irregularly from 0.13 to $0.52 \mathrm{cmolkg}^{-1}$ soil. Calcium varies from 0.8 to $1.6 \mathrm{cmolkg}^{-1}$ while magnesium ranges from 0.2 to $1.2 \mathrm{cmolkg}^{-1}$ soil. The cation exchange is moderate to high, ranging from 11.20 to $18.80 \mathrm{cmolkg}^{-1}$ of soil. It varies irregularly with depth.

Table 1: Physical Properties of Mgbakwu College Soil

\begin{tabular}{|c|c|c|c|c|c|c|c|}
\hline \multirow[t]{2}{*}{ Description } & Depth & Clay & Silt & Fine Sand & Coarse Sand & Total Sand & \multirow{2}{*}{$\begin{array}{l}\text { Texture } \\
\text { Class }\end{array}$} \\
\hline & $\mathrm{Cm}$ & & & $\mathrm{gkg}^{-1}$ & & & \\
\hline \multirow[t]{3}{*}{ ANSCOAM PIT 1} & $0-60$ & 70 & 90 & 390 & 450 & 840 & LS \\
\hline & $60-115$ & 190 & 50 & 350 & 450 & 800 & SL \\
\hline & $115-180$ & 210 & 70 & 320 & 400 & 720 & SCL \\
\hline
\end{tabular}

ANSCOAM = Anambra State College of Agriculture Mgbakwu

\begin{tabular}{|c|c|c|c|c|c|c|c|}
\hline \multirow[t]{2}{*}{ Description } & Depth & Clay & Silt & Fine Sand & Coarse Sand & \multirow[t]{2}{*}{ Total Sand } & \multirow{2}{*}{$\begin{array}{c}\text { Texture } \\
\text { Class }\end{array}$} \\
\hline & $\mathrm{Cm}$ & & & $\mathrm{gkg}^{-1}$ & & & \\
\hline \multirow[t]{3}{*}{ ANSCOAM PIT 2} & $0-60$ & 270 & 50 & 300 & 50 & 750 & SCL \\
\hline & $60-105$ & 290 & 70 & 310 & 330 & 640 & SCL \\
\hline & $105-180$ & 290 & 50 & 370 & 290 & 660 & SCL \\
\hline
\end{tabular}

ANSCOAM = Anambra State College of Agriculture Mgbakwu

The base saturation ranges from 11.22 to $22.1 \%$. The available $\mathrm{P}$ varies irregularly with depth from 1.87 to $3.73 \mathrm{mgkg}^{-1}$. It is low in value. Both the hydrogen and aluminium contributes a relatively equal amount of ions value to the soil $\mathrm{pH}$. Hydrogen irons range from 0.4 to
$2.4 \mathrm{cmolkg}^{-1}$ while aluminium ions ranges from 0.4 to $2.0 \mathrm{cmolkg}^{-1}$. 
Table 2: Chemical Properties of Mgbakwu College Soil

\begin{tabular}{|c|c|c|c|c|c|c|c|c|c|c|c|c|c|c|c|}
\hline Description & $\begin{array}{l}\text { Depth } \\
\text { CM }\end{array}$ & \multicolumn{2}{|c|}{$\mathrm{pH}$} & \multicolumn{3}{|c|}{ Organic Matter } & \multicolumn{4}{|c|}{$\begin{array}{l}\text { Exchangeable Base } \\
\text { cmolkg }^{-1}\end{array}$} & $\begin{array}{l}\text { CEC } \\
\text { cmolkg }^{-1}\end{array}$ & Base Sat. & \multicolumn{3}{|c|}{$\begin{array}{l}\text { Exch. Acidity } \\
\text { cmolkg-1 }^{-1}\end{array}$} \\
\hline & $60-115$ & 5.5 & 4.1 & 0.33 & 0.56 & 0.08 & 0.51 & 0.13 & 1.0 & 1.0 & 12.00 & 22.00 & 1.0 & 1.6 & 2.80 \\
\hline & $115-180$ & 5.6 & 4.1 & 0.04 & 0.07 & 0.04 & 0.25 & 0.26 & 1.0 & 0.2 & 11.20 & 15.27 & 1.2 & 1.0 & 2.80 \\
\hline
\end{tabular}

ANSCOAM = Anambra State College of Agriculture Mgbakwu

\begin{tabular}{|c|c|c|c|c|c|c|c|c|c|c|c|c|c|c|c|}
\hline Description & $\begin{array}{l}\text { Depth } \\
\text { CM }\end{array}$ & \multicolumn{2}{|l|}{$\mathrm{pH}$} & \multicolumn{3}{|c|}{ Organic Matter } & \multicolumn{4}{|c|}{$\begin{array}{l}\text { Exchangeable Bases } \\
\text { cmolkg }^{-1}\end{array}$} & $\begin{array}{l}\text { CEC } \\
\text { cmolkg }^{-1}\end{array}$ & Base Sat. & \multicolumn{2}{|c|}{$\begin{array}{l}\text { Exch. Acidity } \\
\text { cmolkg }^{-1}\end{array}$} & $\begin{array}{c}\mathrm{P} \\
\mathrm{mgkg}^{-1}\end{array}$ \\
\hline & $60-115$ & 5.8 & 4.1 & 0.28 & 0.06 & 0.38 & 0.13 & 0.13 & 1.0 & 0.6 & 18.80 & 11.22 & 0.4 & 2.4 & 1.87 \\
\hline & $115-180$ & 5.8 & 4.2 & 0.20 & 0.35 & 0.07 & 0.15 & 0.39 & 1.6 & 1.2 & 17.60 & 18.98 & 2.0 & 0.2 & 2.80 \\
\hline
\end{tabular}

ANSCOAM = Anambra State College of Agriculture Mgbakwu

\section{DISCUSSION}

The major aims of this work were to characterise the Anambra State College of Agriculture (ANSCOAM) soil at Mgbakwu as a way of giving an insight of the soil potentiality for various agricultural developments. From the result obtained, the soil textures were of medium textured according to the classification range of Esteban (2000). Fine textured soils tend to have structural and infiltration problems, while major limitations for coarse textured soils are lack of nutrients and water holding capacities. The dominance of total sand probable indicates fragility and low content of colloidal materials which eventually might give rise to the susceptibility of the soils to erosion. The $\mathrm{pH}$ of the soils showed strongly acidic to moderate acidic in water, and extremely acidic in $\mathrm{KCl}$. This kind of soil reaction could be attributed to the parent material, and the high leaching ability of the flood plain soils. The drops in $\mathrm{pH}$ value in $\mathrm{KCl}$ probable suggest hydrolysis of $\mathrm{Al}^{3+}$ displaced by $\mathrm{K}^{+}$. This suggests a strong acid condition and substantial presence of aluminium ions (Esu, 2010). The data obtained then suggest that the exchangeable $\mathrm{Al}^{3+}$ contribute to the acidity of the soils of the area. The organic matter content of the soil is very low in value. This may be attributed to high temperature and relative humidity of the area which favour rapid mineralisation of organic matter. The decrease in OC/OM with depth may be due to lack of pronounced influence on the organic horizon by the parent material (Stutter et al., 2003; Manjoka et al., 2007) probable because the soil is greatly affected by the bio cycling of nutrients that involve litter decomposition.

The soil available phosphorous value is very low. This may be due to phosphate fixation which is not restricted to any particular soil kind. Nweke and Nsoanya
(2012) made a similar observation in characterization of Igbariam soils. The values of exchangeable bases are low, with the exception of sodium, which is moderate, and potassium which is low to high in value. This might be attributed to leaching problems as a result of high rain fall. The result equally showed that exchange complexes were occupied mainly by $\mathrm{Ca}$ and $\mathrm{Mg}$. The soil CEC is medium to high and this could be associated to clay and organic matter content and their interactions. The exchangeable acidity of the soils showed low values which suggest absence of the possibility of $\mathrm{Al}^{3+}$ toxicity. The base saturation values of the soil was observed to be low, this could be associated to organic matter content and leaching problems.

The physical and chemical attributes of the soil determines to a great extent their potentials for different development projects. They are very crucial in deciding which crops to grow in the area and the type or nature of soil amendment required to be carried out in the area to achieve an enviable result.

\section{CONCLUSION}

From the findings of this study, Anambra State College of Agriculture, Mgbakwu, soils were found to be loamy sand to sandy clay loam. The soil $\mathrm{pH}$ was found to be strongly to moderate acidic while the OM content, OC and TN and exchangeable bases were also found to be low. The soils of the study area generally were found to be poor in these plant nutrient elements that are index of soil fertility. Therefore, there is need for appropriate soil management strategy through the use of good soil amendments to improve the nutrient status of the soils in order to realise its production capacity. 


\section{REFERENCES}

Akamigbo, F.O.R. (2010). Soils: Fundamental Methods of Soil Resources Survey, Classification, Interpretation and Application. University Book Shop Ltd, UNN.

Bouyoucous, G.J. (1981). A Recaliberation of Hydrometer for Mechanical Analysis of Soils. Agronomy Journal 43:424-438.

Bray, R.H. and L.T. Kurtz. (1945). Determination of Total Organic and Available Form of Phosphorus in Soils. Soil Science 59:39-45.

Bremmer, J.M. and Mulvancy, G.S. (1982). Nitrogen total. In Methods of Soil Analysis Part II, ASA no. 9 Madison, Wisconsin 595 - 624.

Duze, M. and Afolabi, M.A. (1981). Senior School Atlas Macmillan Education Ltd. Nigeria

Esteban, H (2000). Soil test interpretation: Guide A 122, College of Agriculture, Consumer and Environmental Science, New Mexico State University

Esu, I. E. (2010). Soil characterization, classification and survey. Heinemann Educational Books Publishers, Nigeria 232pp
Jackson, M. L (1958). Soil Chemical Analysis and Advance Course Department of Soil Science, University of Wisconsin, Madison USA

Manjoka, J, Yerokun, O. A., Lungu, O. I and Munyinda, $\mathrm{K}$ (2007). Changes in soil organic matter and soil aggregation of a Zambian oxisol after applying lime, Int'l. J. Soil Sci. 2(3): 190-196.

Mclean, E.O. (1982). Soil pH and Time Requirement: Methods of Soil analysis Second Edition, Agronomy Series. No. 9 ASA Madison, WI USA

Nweke, I A and Nsoanya, L N (2012). Inventory of physico-chemical characteristics of soils of the teaching and research farm, faculty of agriculture, Anambra state University, Igbariam campus, Nigeria, In: Proc. Int'l. Agric. Conf. ANSUIAC2012, $6^{\text {th }}-9^{\text {th }}$ May,2012 held at Anambra State University, Igbariam campus.

Stutter, M., Langan, S and Cresser, M. (2003). Weathering and atmospheric deposition signature of basic cations in upland soils of NE Scotland: their application to critical load assessment. Geoderma 116: 301-342

Walkley A and Black I A (1934) Determination organic carbon in soils. Soil Sci. 37: 29 - 38. 